Journal of Thermal Engineering, Vol. 5, No. 4, pp. 293-301, July, 2019

Yildiz Technical University Press, Istanbul, Turkey

\title{
NUMERICAL SIMULATION AND ANALYSIS OF HEAT TRANSFER FOR DIFFERENT GEOMETRIES OF CORRUGATED TUBES IN A DOUBLE PIPE HEAT EXCHANGER
}

\author{
M. Bayareh ${ }^{1, *}$, A. Nourbakhsh ${ }^{2}$
}

\begin{abstract}
In the present study, effect of different geometries of inner and outer tube surfaces on heat transfer of a double pipe heat exchanger is studied. Water-CuO nanofluid, that is assumed to be a single phase, flows in the outer tube. Two-equation standard $\kappa-\varepsilon$ turbulence model is used to model the turbulent flow. Simulations are done for different cases include convex, concave and smooth surfaces for inner and outer tubes at different Reynolds numbers. Results show that the maximum heat transfer corresponds to the convex-concave case in comparison with the smooth-smooth one. Heat transfer rate increases with the Reynolds number, but the slope of the increase for nanofluid is lesser than that for the pure fluid. It is demonstrated that the friction factor decreases with the Reynolds number, so the pressure drop decreases as the Reynolds number increases. Also, the simulations are done for two other nanofluids, water- $\mathrm{ZnO}$ oxide and water- $\mathrm{SiO}_{2}$ dioxide with a volume fraction of $3 \%$. It is found that water-CuO nanofluid flow leads to more heat transfer rate in a double pipe heat exchanger in comparison with the other nanofluids.
\end{abstract}

Keywords: Heat Exchanger, Surface Geometry, Heat Transfer, Nanofluid, Friction Factor

\section{INTRODUCTION}

Heat exchangers are used in most industrial units. Therefore, improving the efficiency and increasing heat transfer have been the subject of considerable studies in recent years. There are two ways to increase heat transfer in a double pipe heat exchangers: the use of curved pipes and nanofluids. The curvature increases the effective surface and the turbulence rate of the fluid flow results in an increase in the heat transfer. Due to the presence of metal and carbon, nanofluids have a higher conductivity rather than non-metallic materials [1]. The increase in the heat transfer coefficient of a nanofluid in comparison with the base fluid depends on the parameters such as the concentration, type and size of the nanoparticles.

Pak and Choi [2] examined the increase in heat transfer due to the presence of aluminum oxide and titanium dioxide nanoparticles in a horizontal circular tube. They found that the heat transfer coefficient of aluminum oxide nanofluid with a volume concentration of $3 \%$ increases by $12 \%$ compared with the pure fluid. Li and Xuan [3] experimentally investigated the heat transfer of water-CuO nanofluid in a tube with constant heat flux for two laminar and turbulent regimes and provided a relation to predict the heat transfer coefficient for these two flow regimes. Yang et al. [4] investigated the increase in the heat transfer coefficient in a horizontal tube heat exchanger and presented a new correlation. They showed that the heat transfer coefficient concluded from their relation is lower than that from $\mathrm{Li}$ and Xuan's equation. Zeinali et al. [5] investigated the effect of water-CuO and water- $\mathrm{Al}_{2} \mathrm{O}_{3}$ nanofluids on heat transfer from a helical tube at a constant temperature. They showed that the heat transfer coefficient increases with volume fraction and the increase is higher for water- $\mathrm{Al}_{2} \mathrm{O}_{3}$ nanofluid. Wen and Ding [6] measured the pressure drop and heat transfer coefficient of water- $\mathrm{Al}_{2} \mathrm{O}_{3}$ nanofluid in a circular tube in a fully developed fluid flow. Their results showed that the nanofluid friction coefficient can be predicted analytically using the Darcy equation for one-phase flows. Vasu et al. [7] studied the affective parameters on heat transfer rate of a compact heat exchanger numerically. They found that the cooling capacity of nanofluid is much higher than that of pure fluid. Pantzali et al. [8] investigated the effect of water-CuO nanofluid on the performance of a small plate heat exchanger (PHE) and concluded that lower power is required for decreasing the pressure drop of nanofluid flow. Hwang et al. [9] investigated the increase of heat transfer in a double pipe heat exchanger with water- $\mathrm{TiO}_{2}$ nanofluid. Kannadasan et al. [10] experimentally investigated

This paper was recommended for publication in revised form by Regional Editor Omid Mahian

${ }^{1}$ Department of Mechatronics Engineering, Shahrekord University, Shahrekord, Iran

${ }^{2}$ Department of Mechanical Engineering, Bu-Ali Sina University, Hamedan, Iran

${ }^{\star}$ E-mail address: m.bayareh@sku.ac.ir

Orcid id: 0000-0002-1821-3771, 0000-0002-7002-6092

Manuscript Received 03 January 2018, Accepted 09 March 2018 
the heat transfer of the nanofluid and pressure drop of water-CuO in a helical heat exchanger. They reported that nanofluids with the volume fraction of $1 \%$ and $2 \%$ results in an increase in Nusselt number equal to $37 \%$ and $49 \%$, respectively. In another experimental investigation, Zamzamian et al. [11] examined the effect of two nanofluids ethylene glycol- $\mathrm{Al}_{2} \mathrm{O}_{3}$ and ethylene glycol-CuO on heat transfer of forced convection in a double pipe heat exchanger. Huminic and Huminic [12] numerically studied the heat transfer of water- $\mathrm{CuO}$ and water- $\mathrm{TiO}_{2}$ nanofluids in a spiral double pipe heat exchanger under laminar flow. They concluded that the increase in the volume fraction of nanoparticles results in increasing heat transfer.

In the present work, the geometry effect on thermal performance of a double pipe heat exchanger is studied. The working fluid is considered to be a nanofluid. In other words, both proposed methods are used to increase the heat transfer in the heat exchanger. The simulations are performed by using ANSYS FLUENT 6 commercial software. The main objective of the present study is determination of the optimum geometry for corrugated tubes by numerical simulations. In addition, the influence of water- $\mathrm{ZnO}$ and water- $\mathrm{SiO}_{2}$ nanofluids on heat transfer rate of the heat exchanger is studied. A numerical simulation result is compared with experimental results and the pressure drop and Nusselt number are presented in this regard.

\section{GOVERNING EQUATIONS}

The flow is assumed to be steady and incompressible with constant physical properties. Based on the above assumptions, the mass conservation equation (continuity equation) is as follows [13]:

$$
\frac{\partial}{\partial x_{i}}\left(\rho u_{i}\right)=0
$$

The Navier-Stokes equations are expressed as:

$$
\frac{\partial}{\partial t}\left(\rho u_{i}\right)+\frac{\partial}{\partial x_{j}}\left(\rho u_{i} u_{j}\right)=-\frac{\partial p}{\partial x_{i}}+\frac{\partial \tau_{i j}}{\partial x_{j}}
$$

The energy equation is simplified as follows:

$$
\frac{\partial}{\partial t}\left(\rho c_{P} T\right)+\frac{\partial}{\partial x_{j}}\left(\rho c_{P} u_{j} T\right)=\frac{\partial}{\partial x_{j}}\left(k \frac{\partial T}{\partial x_{j}}\right)
$$

The SIMPLE algorithm is used for coupling the velocity and pressure equations. The equations are discretized by the finite-volume method. The second-order upwind is employed for spatial discretization of the velocity components. Also, the second order central difference scheme is used for spatial discretization of density.

The nanofluid flow can be modeled using single-phase or two-phase methods. Here, a single-phase model is used which involves defining the effective properties of nanofluid as follows [13]:

$$
\begin{gathered}
\rho_{n f}=(1-\varphi) \rho_{b f}+\varphi \rho_{p} \\
\left(\rho C_{p}\right)_{n f}=\frac{(1-\varphi)\left(\rho C_{p}\right)_{b f}+\varphi\left(\rho C_{p}\right)_{p}}{(1-\varphi) \rho_{b f}+\varphi \rho_{p}} \\
\frac{\mu_{n f}}{\mu_{b f}}=123 \varphi^{2}+7.3 \varphi+1
\end{gathered}
$$


Thermophysical properties of the nanofluids used in the present simulations are presented in Table 1. The flow nature and also the range of Reynolds numbers used in the simulations result in turbulent flow. Therefore, the turbulence is modeled using the standard $\kappa-\varepsilon$ model, where $\kappa$ is kinetic energy of turbulence and $\varepsilon$ is the dissipation rate. The transition equations of $\kappa$ and $\varepsilon$ are defined as follows, respectively [14]:

$$
\begin{gathered}
\frac{\partial}{\partial t}(\rho \kappa)+\frac{\partial}{\partial x_{i}}\left(\rho k u_{i}\right)=\frac{\partial}{\partial x_{i}}\left[\left(\mu+\frac{\mu_{t}}{\sigma_{k}}\right) \frac{\partial \kappa}{\partial x_{i}}\right]+G_{\kappa}-\rho \varepsilon \\
\frac{\partial}{\partial t}(\rho \varepsilon)+\frac{\partial}{\partial x_{i}}\left(\rho \varepsilon u_{i}\right)=\frac{\partial}{\partial x_{i}}\left[\left(\mu+\frac{\mu_{t}}{\sigma_{\varepsilon}}\right) \frac{\partial \varepsilon}{\partial x_{i}}\right]+\frac{\varepsilon}{k}\left(C_{1 \varepsilon} G_{\kappa}-C_{2 \varepsilon} \varepsilon\right)
\end{gathered}
$$

where, $G_{\kappa}$ is the production of kinetic energy due to the velocity gradient. Also, the value of the constant coefficients is as follows:

$$
C_{1 \varepsilon}=1.44, C_{2 \varepsilon}=1.92, C_{\mu}=0.09 \text {. }
$$

Table 1. Thermophysical properties of water and nanofluids [16]

\begin{tabular}{|c|c|c|c|c|}
\hline Type of fluids & $K(W / m K)$ & $C_{\mathrm{p}}(\mathrm{J} / \mathrm{kgK})$ & $\rho\left(\mathrm{kg} / \mathrm{m}^{3}\right)$ & $P r$ \\
\hline Pure water & 0.613 & 4179 & 997.1 & 6.2 \\
\hline $\mathrm{CuO}$ & 77 & 540 & 6510 & - \\
\hline $\mathrm{TiO}_{2}$ & 8.37 & 710 & 3840 & - \\
\hline $\mathrm{ZnO}$ & 29 & 1255 & 5606 & - \\
\hline
\end{tabular}

\section{RESULTS AND DISCUSSION}

The heat exchanger includes two inner and outer tubes. Cold nanofluid flows through the outer tube and hot water flows through the inner one. Different corrugated tubes are considered to compare with the smooth tube surfaces. The effect of these geometries on heat transfer in a double pipe heat exchanger is investigated numerically. Water$\mathrm{CuO}$ nanofluid is the working fluid. Based on the experimental results of Sadighi et al. [15] who considered seven new types of corrugated tubes for a double pipe heat exchanger, in the present work, the same geometries are examined numerically in the presence of the nanofluid. Different arrangements of tubes are shown in Table 2. Dimensionless hydraulic diameter $\left(D^{*}\right)$ is defined as the ratio of the hydraulic diameter and the diameter of the inner tube $(D)$.

Table 2. Tube arrangements in the present study

\begin{tabular}{|c|c|c|c|}
\hline Cases & Inner tube & Outer tube & $D^{*}$ \\
\hline A & Smooth & Smooth & 0.82 \\
\hline B & Convex & Smooth & 0.67 \\
\hline C & Convex & Convex & 0.82 \\
\hline D & Concave & Smooth & 0.98 \\
\hline E & Concave & Concave & 0.82 \\
\hline F & Convex & Concave & 0.51 \\
\hline G & Concave & Convex & 1.14 \\
\hline
\end{tabular}


To ensure the accuracy of the simulations, the arrangement $\mathrm{D}$ is compared with the experimental results of Sadighi et al. [15]. The schematic of the problem is shown in Figure 1. The Nusselt number $\left(N u=h(x) D_{h} / k_{f}\right)$ as a function of Reynolds number $\left(\operatorname{Re}=\rho_{f} v D_{h} / \mu_{f}\right)$ is shown in Figure 2.

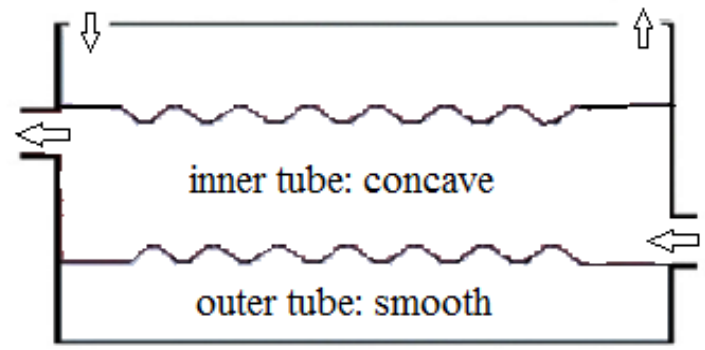

Figure 1. Schematic illustration of arrangement D

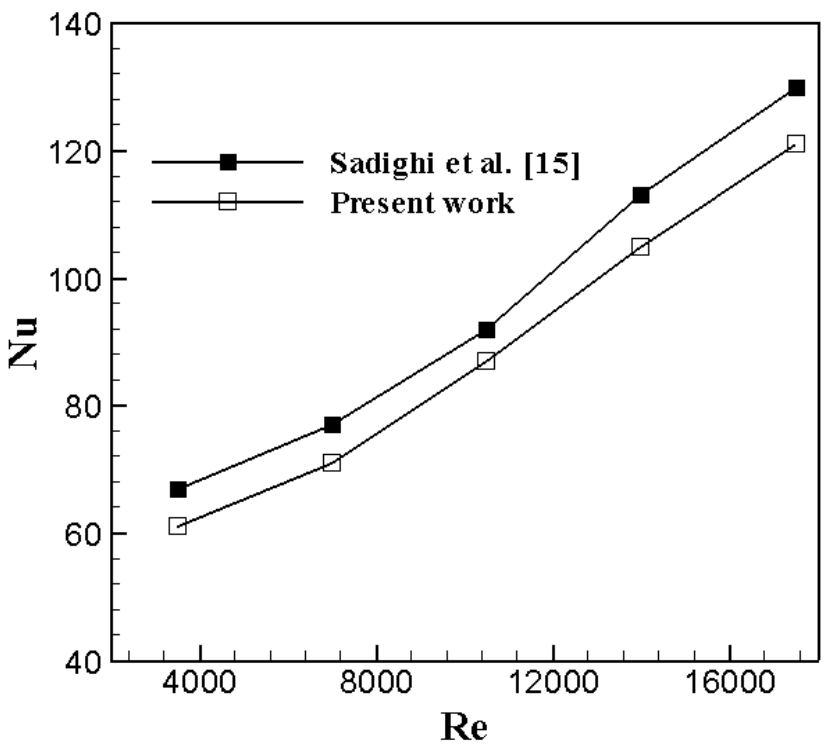

Figure 2. Nusselt number versus Reynolds number for the arrangement D

Figure 2 shows that the Nusselt number increases with increasing the Reynolds number. It can be seen that there is a good agreement between the values obtained from the present simulation and experimental results of Sadighi et al. [15]. The maximum error is related to the Reynolds number 17500 and equal to $8.6 \%$.

Because the computational cost of each simulation directly relates to the number of grid points, the number of nodes is required to determine an appropriate grid resolution. For this reason, four different computational grids is considered to simulate the arrangement D. Figure 3 illustrates that 222164 grid resolution has a very small difference with the smallest mesh results (285580 grid resolution). In the next section, the simulations for the seven different geometries will be presented by using the computational domain with 222164 grid points.

\section{Effect of tube surface geometry}

In this section, water- $\mathrm{CuO}$ nanofluid is assumed as the working fluid (of $3 \%$ volume fraction) in the external tube and water is considered as the internal tube working fluid. The heat transfer rate and the efficiency of the heat exchanger is calculated and compared with each other for different tube surface arrangements. The variation of the Nusselt number in terms of Reynolds number is plotted in Figure 4 for different geometries of corrugated tubes. 
Comparison of the results shows that the highest amount of Nusselt number belongs to the F-type heat exchanger, which has a convex interior tube surface and a concave outer tube surface. As expected, this result is qualitatively consistent with the result of Sadighi et al. [15]. The reason for this increase in heat transfer can be explained as follows: The outer tube with a concave surface drives the cold nanofluid to the inside of the inner tube, and the inner tube with the convex surface do a reverse action. For this reason, further mixing takes place and the heat transfer rate increases. Due to the fact that the nanofluid is enclosed between two concave and convex surfaces with a smaller cross-section, the turbulence of the flow is more intense. Obviously, using the nanofluid in the outer tube leads to an increase in the heat transfer rate. In addition, it can be seen that with the increase of the Reynolds number results in an increase in the heat transfer rate for all arrangements. Since the Nusselt number is directly related to the Reynolds number, the last result was expected, but the slope of the curves is different in Figures 3 and 4 . The increase in the Nusselt number when the nanofluid flows in the outer tube is less than that the water flows as the operating fluid in inner and outer tubes. In other words, the dependence of the Nusselt number on the Reynolds number for the case of being nanofluid as a working fluid is less than that of employing water as the working fluid in outer tube.

Now, the percentage increase in the Nusselt number in tubes with at least one curved surface is investigated at different Reynolds numbers and is compared with the case of the smooth surfaces of the tubes. In Figure 5, Nu* is defined as the ratio of the Nusselt number for the arrangements B to $G$ and the Nusselt number corresponding to the arrangement $\mathrm{A}$. This figure shows that the percentage increase of heat transfer decreases with increasing Reynolds number. This result is also qualitatively consistent with experimental results of Sadighi et al. [15]. Similar to their results, current simulations demonstrates that the slope of increasing of the Nusselt number depends on the geometry of the surfaces of the inner and outer tubes. The slope is large for the cases in which there are more curved surfaces. This is low for the cases in which at least one of the surfaces is smooth. In addition, as already mentioned, the percentage increase in the Nusselt number in the present work at different Reynolds numbers and for various geometries is less than that reported by Sadighi et al. [15].

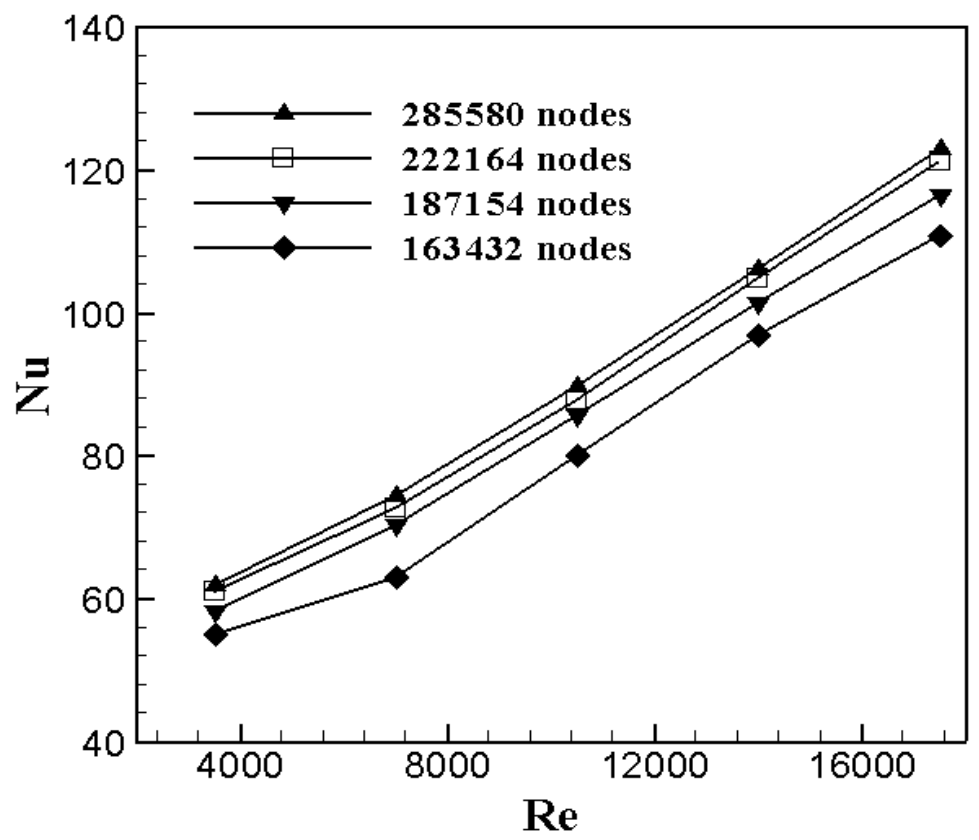

Figure 3. Nusselt number versus Reynolds number for different computational grids 


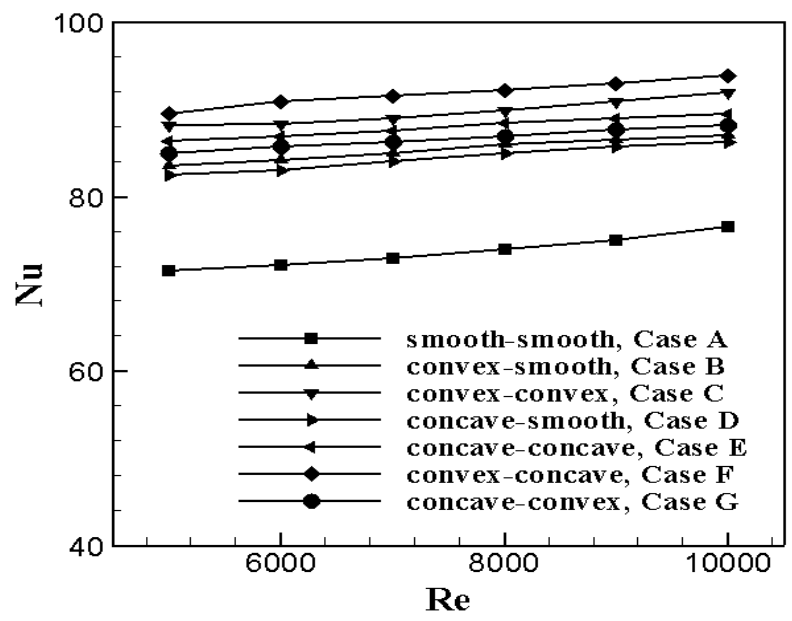

Figure 4. Nusselt number versus Reynolds number for different arrangements

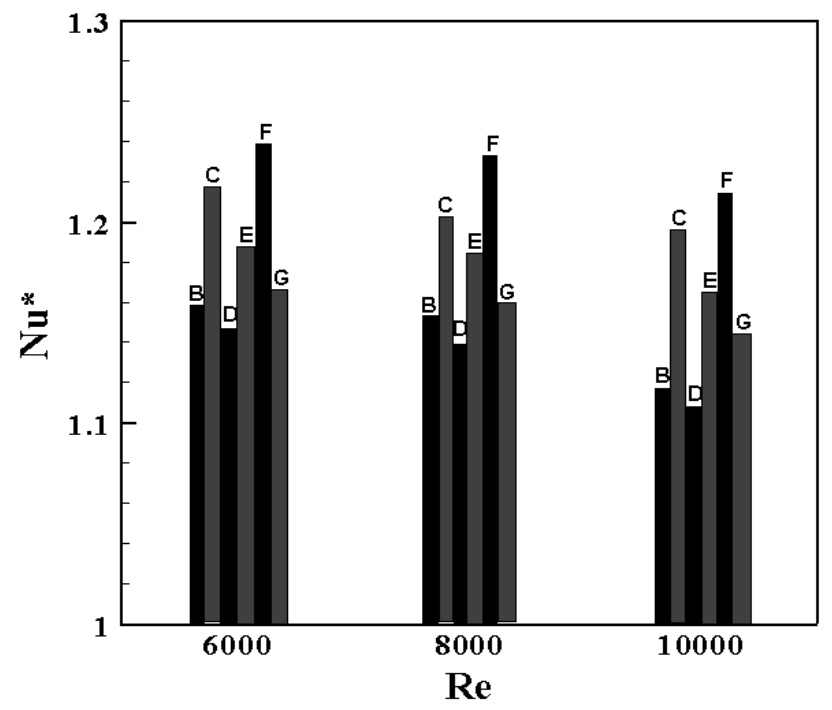

Figure 5. Nusselt number versus Reynolds number for different arrangements in comparison with smooth tube surfaces

The pressure drop is another important factor in the design of heat exchangers. Since the coefficient of friction is directly related to the pressure drop, the variation of this coefficient shows the variation of pressure drop in each of the above geometries. The coefficient of friction $f$ is defined as [15]:

$$
f=\frac{\Delta p D_{h}}{L \rho V^{2}}
$$

where, $L$ is heat exchanger length.

Figure 6 shows the variation of the friction coefficient in terms of the Reynolds number for different arrangements of the heat exchanger tube surfaces. It can be concluded that the friction coefficient decreases with increasing the Reynolds number. At a constant Reynolds number, the friction coefficient depends on the surface curvature. For example, a convex surfaces leads to larger coefficient of friction in comparison with other corrugated surfaces.

Compared to the case in which water is used as a working fluid in the heat exchanger, the value of friction factor show is higher for the same geometries. For example, in the Reynolds number of 10,000, Sadighi et al. [15] 
reported $f=0.15$ for convex-convex arrangement (type $\mathrm{F}$ ) while this value is 0.22 in the present work. This difference is due to the higher viscosity of the nanofluid compared to the base fluid. In this figure, the slightly slope of the changes is observed similar to Figure 4.

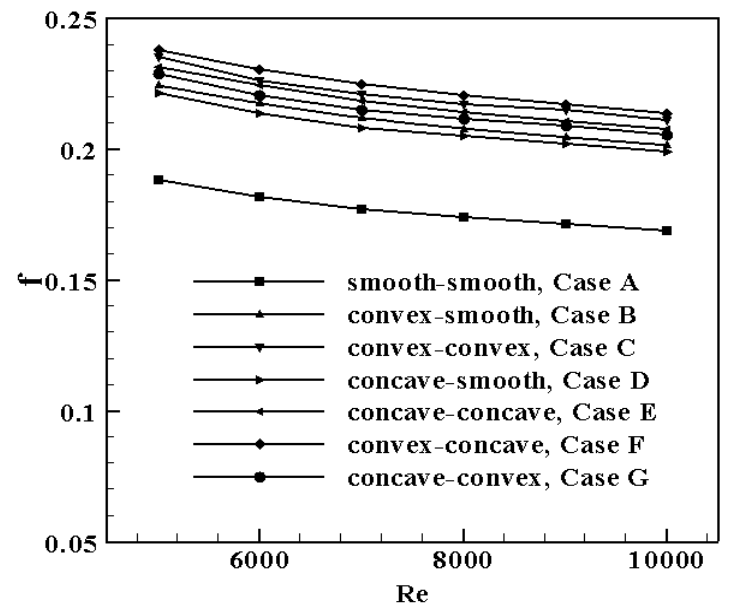

Figure 6. Friction factor versus Reynolds number for different arrangements.

\section{Effect of nanofluid}

In this section, in addition to the water- $\mathrm{CuO}$ nanofluid, two nanofluids are considered as the working fluid: water- $\mathrm{ZnO}$ and water- $\mathrm{SiO}_{2}$. The volume fraction of these two nanofluids is also $3 \%$. Figure 7 shows the results to explore the effect of the nanofluid. This figure represents a significant increase in the heat transfer rate in the heat exchanger when a nanofluid is used as a working fluid especially at low Reynolds numbers. As expected, using the water- $\mathrm{CuO}$ nanofluid concludes the highest Nusselt number due to higher thermal conductivity of copper.

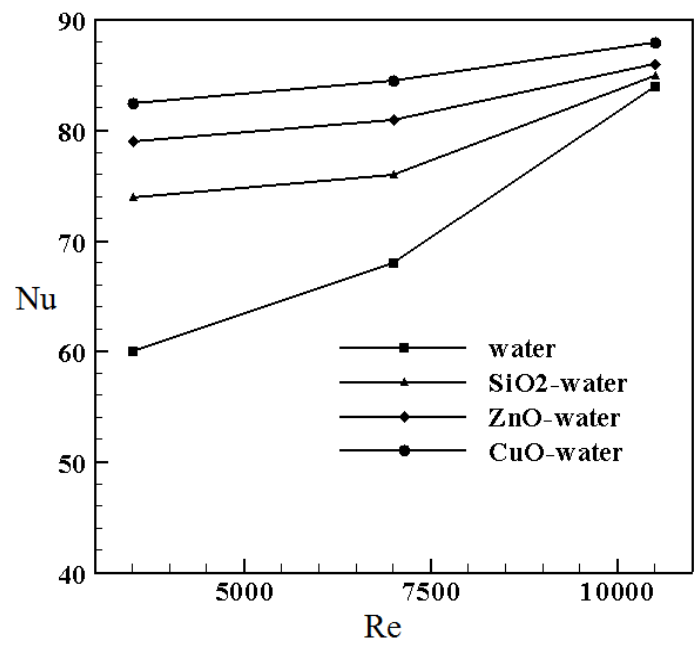

Figure 7. Nusselt number versus Reynolds number for different nanofuids.

\section{CONCLUSIONS}

The effect of tube surface geometry of a double pipe heat exchanger was investigated for seven different arrangements in the presence of a nanofluid that flows in the outer tube. The results of the simulations showed that the heat transfer rate increases with the Reynolds number. The rate of the increase is smaller in comparison with the case 
in which water is a working fluid. It was found that the arrangement in which the inner tube is convex and the outer one is concave leads to the highest heat transfer rate. This is because of the effect of turbulence and higher rate of mixing. In general, as the tube surfaces are more curved, the Nusselt number increases. However, when the nanofluid is used as a working fluid, a significant result was obtained: when the working fluid in outer tube is nanofluid, the dependence of the Nusselt number on the Reynolds number decreases in comparison with the case in which water is the working fluid. In order to investigate the effect of nanofluid, two other nanofluids were also considered when the surface of the inner tube surface was concave and the outer one was smooth. The results showed that water-CuO nanofluid results in higher heat transfer in comparison with water- $\mathrm{ZnO}$ and water- $\mathrm{SiO}_{2}$ nanofluids due to higher copper thermal conductivity.

\section{NOMENCLATURE}

$\begin{array}{cl}C_{p} & \text { Specific heat at constant pressure, } \mathrm{J} / \mathrm{kg} \mathrm{K} \\ D_{h} & \text { Hydraulic diameter, } \mathrm{m} \\ f & \text { Friction factor } \\ G_{\kappa} & \text { Turbulence kinetic energy, } \mathrm{J} \\ h & \text { Convective heat transfer coefficient, } \mathrm{W} / \mathrm{m}^{2} \mathrm{~K} \\ k & \text { Thermal conductivity, W/m K } \\ \mathrm{L} & \text { Heat exchanger length, } \mathrm{m} \\ \mathrm{Nu} & \text { Nusselt number } \\ p & \text { Pressure, Pa } \\ \mathrm{t} & \text { Time, } \mathrm{s} \\ \mathrm{T} & \text { Temperature, } \mathrm{K} \\ \mathrm{u} & \text { Velocity field, } \mathrm{m} / \mathrm{s} \\ \mathrm{X} & \text { Position, } \mathrm{m} \\ \mu & \text { Viscosity, } \mathrm{kg} / \mathrm{m} . \mathrm{s} \\ \rho & \text { Density, } \mathrm{kg} / \mathrm{m}^{3} \\ \tau & \text { Shear stress, Pa } \\ b f & \text { Base fluid } \\ n f & \text { nanofluid } \\ p & \text { particle }\end{array}$

\section{REFERENCES}

[1] Choi, S. U., and Eastman, J. A. (1995). Enhancing thermal conductivity of fluids with nanoparticles (No. ANL/MSD/CP-84938; CONF-951135-29). Argonne National Lab., IL (United States).

[2] Pak, B. C., and Cho, Y. I. (1998). Hydrodynamic and heat transfer study of dispersed fluids with submicron metallic oxide particles. Experimental Heat Transfer an International Journal, 11(2), 151-170.

[3] Li, Q., and Xuan, Y. (2002). Convective heat transfer and flow characteristics of Cu-water nanofluid. Science in China Series E: Technolgical Science, 45(4), 408-416.

[4] Yang, Y., Zhang, Z. G., Grulke, E. A., Anderson, W. B., and Wu, G. (2005). Heat transfer properties of nanoparticlein-fluid dispersions (nanofluids) in laminar flow. International Journal of Heat and Mass Transfer, 48(6), 1107-1116.

[5] Heris, S. Z., Etemad, S. G., and Esfahany, M. N. (2006). Experimental investigation of oxide nanofluids laminar flow convective heat transfer. International Communications in Heat and Mass Transfer, 33(4), 529-535.

[6] Wen, D., and Ding, Y. (2004). Experimental investigation into convective heat transfer of nanofluids at the entrance region under laminar flow conditions. International journal of heat and mass transfer, 47(24), 5181-5188.

[7] Velagapudi, V., Konijeti, R. K., and Aduru, C. S. K. (2008). Empirical correlations to predict thermophysical and heat transfer characteristics of nanofluids. Therm. Sci, 12(2), 27-37.

[8] Pantzali, M. N., Mouza, A. A., and Paras, S. V. (2009). Investigating the efficacy of nanofluids as coolants in plate heat exchangers (PHE). Chemical Engineering Science, 64(14), 3290-3300.

[9] Hwang, K. S., Jang, S. P., and Choi, S. U. (2009). Flow and convective heat transfer characteristics of water-based A12O3 nanofluids in fully developed laminar flow regime. International journal of heat and mass transfer, 52(1-2), 193-199. 
[10] Kannadasan, N., Ramanathan, K., and Suresh, S. (2012). Comparison of heat transfer and pressure drop in horizontal and vertical helically coiled heat exchanger with $\mathrm{CuO} /$ water based nano fluids. Experimental Thermal and Fluid Science, 42, 64-70.

[11] Zamzamian, A., Oskouie, S. N., Doosthoseini, A., Joneidi, A., and Pazouki, M. (2011). Experimental investigation of forced convective heat transfer coefficient in nanofluids of Al2O3/EG and $\mathrm{CuO} / \mathrm{EG}$ in a double pipe and plate heat exchangers under turbulent flow. Experimental Thermal and Fluid Science, 35(3), 495-502.

[12] Huminic, G., and Huminic, A. (2011). Heat transfer characteristics in double tube helical heat exchangers using nanofluids. International Journal of Heat and Mass Transfer, 54(19-20), 4280-4287.

[13] Azari, A., Kalbasi, M., and Rahimi, M. (2014). CFD and experimental investigation on the heat transfer characteristics of alumina nanofluids under the laminar flow regime. Brazilian Journal of Chemical Engineering, 31(2), 469-481.

[14] Kumar, P., and Ganesan, R. (2012). A CFD study of turbulent convective heat transfer enhancement in circular pipeflow. International Journal of Civil and Environmental Engineering, 6, 385-392.

[15] Dizaji, H. S., Jafarmadar, S., and Mobadersani, F. (2015). Experimental studies on heat transfer and pressure drop characteristics for new arrangements of corrugated tubes in a double pipe heat exchanger. International Journal of Thermal Sciences, 96, 211-220.

[16] Rudyak, V. Y., and Minakov, A. V. (2018). Thermophysical properties of nanofluids. The European Physical Journal E, 41(1), 15. 